\title{
АНАЛИЗ ПРОЦЕССА РЕНТГЕНОЛЮМИНЕСЦЕНТНОЙ СЕПАРАЦИИ АЛМАЗОСОДЕРЖАЩИХ РУД КАК ОБЪЕКТА АВТОМАТИЗАЦИИ
}

\section{ANALYSIS OF X-RAY LUMINESCENT SEPARATION OF DIAMOND ORES AS AN AUTOMATION OBJECT}

\section{Yu.Podkamenny \\ Yu. Bebikhov \\ A. Semenov \\ V. Spiridonov}

Summary. The paper discusses the basic principles of $\mathrm{X}$-ray luminescent separation of diamond ores as an automation object and analyzes moderntechnical solutions and basic organizational and technical issues, the solution to which will contribute to the effective implementation of automated control systems in separation. The complex automation systems of processing plants (ore mills) are described. The process and principle of operation of the $X$-ray luminescent separator of diamond ores are described. It is expedient to automate the $X$-ray luminescent separation using an automated control system. The issues of designing an automated control system with a human-machine interface are considered. An APCS system and an interface of the automated operator-technologist workstation, upgraded through implementing RSLogix 5000 and FactoryTalk View production management software are described.

Keywords: automated control, process, X-ray luminescent separation, processing plant, mining enterprise, diamond ore.

\section{Введение}

ырьевая база алмазосодержащих кимберлитовых руд России является наиболее крупной в мире и представлена коренными, россыпными и техногенными месторождениями, основная часть запасов которых сосредоточена в Западном регионе Якутии [1]. На горно-обогатительные комбинаты (ГОК) этого региона приходится основной объем добычи
Подкаменный Юрий Александрович К.т.н., доцент, Политехнический институт (филиал) СВФУ им. М.К. Аммосова, г. Мирный mirniy.yuriy@mail.ru

Бебихов Юрий Владимирович К.ф.- м.н., дочент, Политехнический институт (филиал) СВФУ им. М.К. Аммосова, г. Мирный bebikhov.yura@mail.ru

Семёнов Александр Сергеевич

К.ф.- м.н., Политехнический институт (филиал) СВФУ им. М.К. Аммосова, г. Мирный sash-alex@yandex.ru

Спиридонов Валентин Михайлович Политехнический институт (филиал) СВФУ им. М.К. Аммосова, г. Мирный kafeiagp@rambler.ru

Аннотация. В статье рассмотрены основные принципы автоматизации рентгенолюминесцентного разделения алмазосодержащих руд как объекта автоматизации, проанализированы современные технические решения, а также основные организационные и технические проблемы, решение которых будет способствовать эффективному внедрению автоматизированных систем управления технологическим процессом сепарации. Описаны комплексные системы автоматизации на перерабатывающих предприятиях (обогатительных фабриках). Приведено описание процесса и принцип работы рентгенолюминесцентного сепаратора алмазосодержащих руд. Автоматизацию рентгенолюминесцентного разделения целесообразно решать с помощью системы автоматического управления. Рассмотрены вопросы проектирования системы автоматического управления с человеко-машинным интерфейсом. Представлена модернизированная система АСУ ТП, а также обновленный интерфейс автоматизированного рабочего места оператора-технолога, за счет внедрения программного обеспечение RSLogix 5000 и информационной системы управления промышленным производством FactoryTalk View.

Ключевые слова: автоматическое управление, технологический процесс, рентгенолюминесцентная сепарация, обогатительная фабрика, горное предприятие, алмазосодержащая руда.

алмазов [2]. Все обогатительные фабрики данных ГОК имеют схожую технологическую цепочку рудоподготовки, которая включает в себя следующие элементы: первичное дробление; классификацию по крупности; вторичное дробление (измельчение); рентгенолюминесцентную сепарацию; тяжелосредную сепарацию; ручную сортировку [3]. В случае большого выхода алмазов класса 1 мм применяют флотацию в машинах пенной сепарации. 
Основным методом по извлечению алмазов из кимберлитовых руд является рентгенолюминесцентная сепарация [4-6]. До настоящего времени остаются нерешенными вопросы повышения производительности по товарному классу в процессе сепарации руд, повышения качества работы рентгенолюминесцентной сепарации и безотказности её функционирования. Указанные проблемы целесообразно решать путём использования автоматической системы управления технологическим процессом (АСУ ТП) рентгенолюминесцентной сепарации (РЛС).

\section{Цель и залачи исслеАования}

Целью исследования процесса является повышение производительности по товарному классу в процессе РЛС, повышение качества работы рентгенолюминесцентных сепараторов и безотказности их функционирования, путем проектирования, разработки и внедрения АСУ ТП, применение резервов оборудования, настройкой позиционирования и отладки систем сепарации.

Задачами исследования является разработка автоматизированного способа управления РЛС алмазосодержащих руд, разработка и исследование систем автоматического регулирования загрузки сепаратора, разработка автоматизированного рабочего места управления сепаратором, настройка параметров критериев для разделения селективного режима работы сепаратора.

Как объект управление взят контур РЛС, где происходит извлечение полезных компонентов (алмазов) в концентрационный отсек.

\section{Результаты исслеАования}

Технология проиеесса обогащения. Обогащение алмазосодержащих руд имеет ряд особенностей по сравнению с обогащением других полезных ископаемых. Эти особенности обусловлены чрезвычайно низким содержанием алмазов в исходном сырье (всего около 0,000005\%), их хрупкостью и большой ценностью $[7,8]$. Последнее обстоятельство требует применения таких процессов обогащения, которые обеспечили бы высокую степень извлечения алмазов из руд [9].

Технологическая схема обогащения алмазосодержащих руд обычно включает следующие операции: рудоподготовку исходного сырья для освобождения алмазов от их связи с другими компонентами, которая состоит из процессов дробления [10], измельчения, грохочения, классификации, обесшламливания, извлечение алмазов из первичных концентратов (доводка) [11].
Отработанный рудный материал, проходя несколько стадий обогащения и измельчения, транспортируется при помощи насосов в отвальные хвосты хвостохранилище.

Дробление - способ освобождения кристаллов алмазов от вмещающих пород. Однако он обладает существенным недостатком: кристаллы алмазов могут переизмельчиться или в них могут образоваться трещины. Чтобы не повредить алмазы, не допускают большой степени дробления. Обычно она не превышает 5 мм³. Для дробления твердой коренной породы применяются щековые дробилки. Для измельчения твердых пород целесообразно применение мельниц мокрого самоизмельчения (МMC), которые вскоре будут заменены на скрубер-бутары, вследствие перехода на глубокие горизонты, где большое содержание глинистых минералов в породе. Исходная руда доставляется до фабрики автотранспортом со склада руды и разгружается в приемные бункеры корпуса крупного дробления фабрики. Пластинчатыми питателями материал загружается в щековые дробилки и ленточными конвейерами подается на дезинтеграцию в скруббер-бутара. Продукт разгрузки скруббер-бутара грунтовыми насосами транспортируется на первую стадию грохочения, где рассев материала осуществляется на классы -35+16 мм,-16+5 мм, и -5 мм. Классификация измельченной породы обеспечивает своевременный вывод раскрытых кристаллов из процесса, что не допускает их переизмельчения и потерь с отвальными хвостами. Материал крупностью -35+16 мм и -16+5 мм поступает на обогащение в рентгенолюминесцентные сепаратоpы.

Концентраты РЛС направляются в цех доводки фабрики. Хвосты РЛС поступают в циркуляцию на доизмельчение. Материал крупностью -5 мм насосами перекачивается на вторую стадию грохочения, где рассев осуществляется на классы -5+2 мм и -2+0,5 мм. Материал крупностью -5+2 мм поступает на установку тяжолосредной сепарации или на отсадочную машину. Отсадкой называется процесс разделения смеси минеральных зерен по плотности. Расслоение осуществляется в водной среде в результате попеременного действия выходящих и нисходящих потоков, вызывающих чередование периодов разрыхления и уплотнения материала. Тяжелые минералы при этом концентрируется в нижнем слое, примыкающем к решету, а легкие в верхнем слое. Концентрат тяжолосредной сепарации или отсадки направляется на участок доводки фабрики, где доводится на РЛС, хвосты которых проходят контрольную липкостную сепарацию. Хвосты липкостной сепарации вместе с хвостами тяжолосредной установки и отсадочной машины поступают в циркуляцию на доизмельчение. 

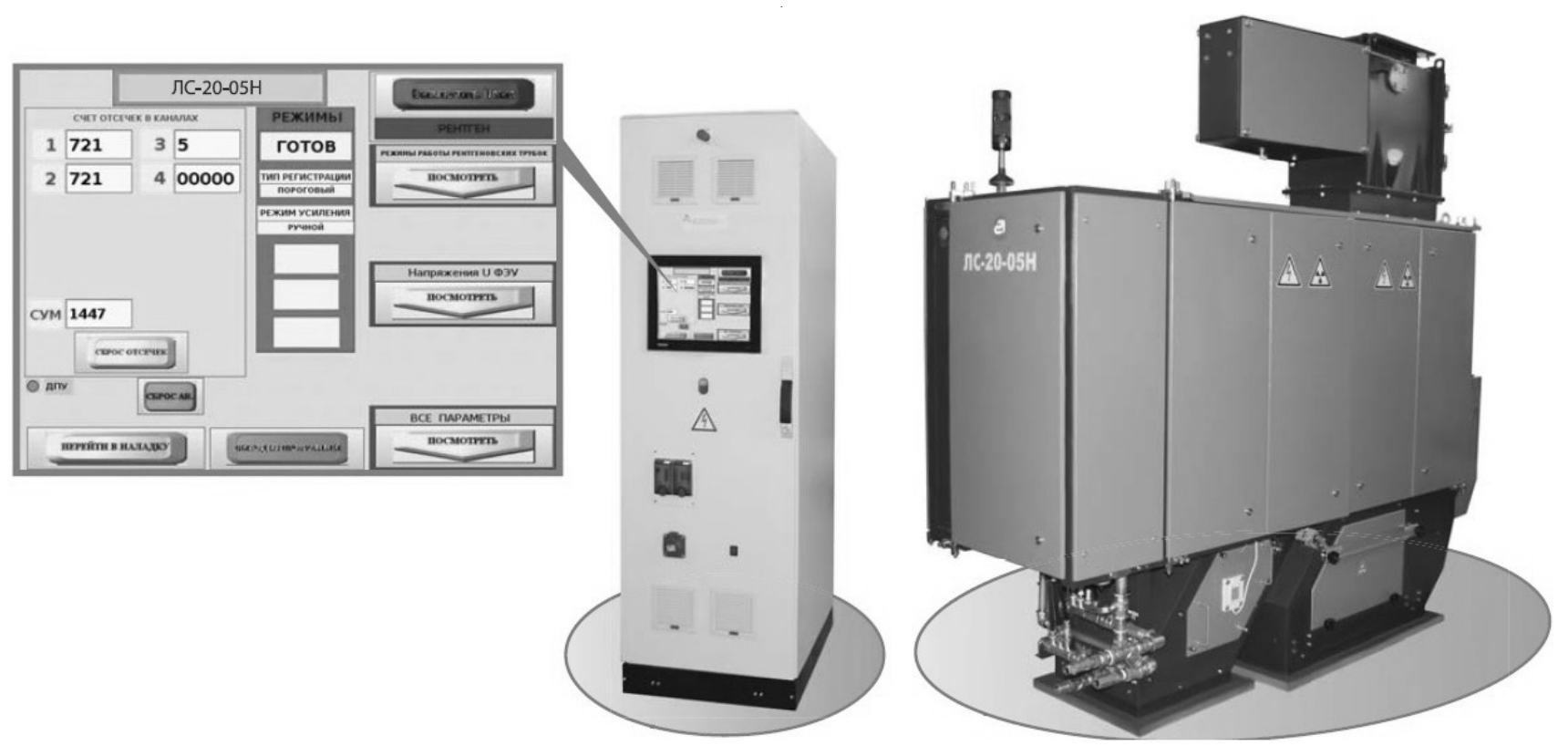

Рис. 1. Внешний вид рентгенолюминесцентного сепаратора

Отработанный рудный материал, проходя несколько стадий обогащения, транспортируется при помощи насосов в отвальные хвосты (хвостохранилище).

В процессе грохочения происходит разделения по классам крупности -50+32 мм,-32+16 мм,-16+6 мм,-6+3 мм и -3+1 мм. Руда поступает в бункеры РЛС, где происходит замер верхнего и нижнего уровней. Далее руда поступает в сепаратор, где происходит разделение по люминесцентному признаку на концентрат и хвостовые продукты. Также для транспортировки руды применяется технологическая вода.

Сепаратор ЛС-20-05Н предназначен для обогащения мокрой исходной алмазосодержащей руды крупностью -20+10 мм и -10+5 мм. Принцип работы сепаратора основан на использовании свойства алмазов люминесцировать под воздействием рентгеновского излучения и различия этих свойств у алмазов и сопутствующих люминесцирующих минералов. Сепаратор состоит из сортировочной машины (MC) и стойки автоматического управления (САУ). Внешний вид рентгенолюминесцентного сепаратора ЛС-20-05 представлен на рисунке 1.

Схема работы сепаратора представлена на рисунке 2. МС и САУ соединены между собой комплектом кабелей длиной 30 м. К МС присоединяются магистрали исходного питания сепаратора, отводы концентрата и хвостов, подводы охлаждающей воды, транспортной воды и сжатого воздуха. Информация о расположении мест присоединения внешних магистралей и видах фи- деров приведена на установочном чертеже MC и габаритном чертеже сепаратора.

Обогащаемый материал - алмазосодержащее сырье, поступает в сепаратор через гравитационный питатель: щелевое отверстие, перекрываемое пневмоуправляемым затвором - шибером. Ширина раскрытия шибера задает производительность сепаратора. Под действием силы тяжести материал падает на формирующий наклонный лоток (ФНЛ), орошается транспортной водой и самотеком поступает в зону возбуждения и регистрации. Возбуждение люминесценции производится импульсами рентгеновского излучения длительностью 0,5 мс с частотой следования 250 Гц. Для обеспечения высокого извлечения организовано облучение потока двумя рентгеновскими трубками (РТ) сверху и снизу. Импульсы тормозного рентгеновского излучения, испускаемого РТ, возбуждают в обогащаемом материале излучение в оптическом диапазоне люминесценцию. Люминесцируют как алмазы, так и ряд других сопутствующих минералов: циркон, кальцит, плагиоклаз и др. Люминесцирует также воздух в зоне регистрации.

Автоматизация проиесса сепарац̧ии. Работа системы контролируется датчиками. Далее рассмотрим эти процессы, как единый управляемый объект. При автоматизации процесса рентгенолюминесцентной сепарации необходимо решать следующие задачи:

1. Автоматический контроль состояния оборудования: давление в магистралях подачи воды и воздуха; параметров их системы; состояния пе- 


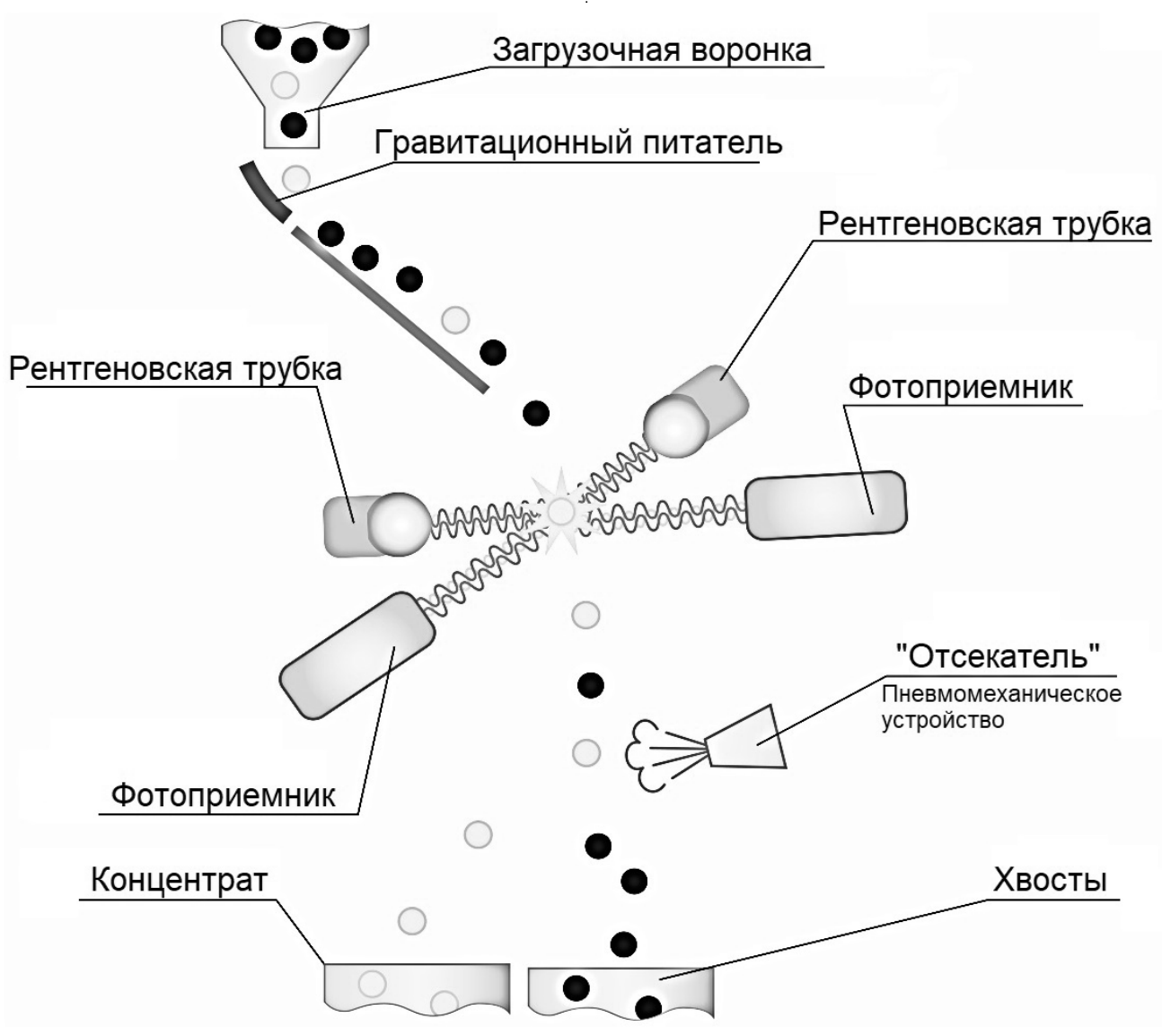

Рис. 2. Схема работы рентгенолюминесцентного сепаратора

регрузочных узлов; длительность работы и простоя технологических механизмов [12].

2. Автоматический контроль технологических параметров сепарации: производительность по исходной руде; расход воды, подаваемый в сепаратор; расход воздуха [13].

3. Автоматическое управление сепарацией: стабилизация технологических параметров; оптимизацией работы [14].

Для успешного выполнения задач автоматизации процессом РЛС необходима специальная подготовка оборудования (оснащение водных и воздушных магистралей регулирующими клапанами, вентилями и т.д.).

Алмазосодержащая руда проходит непрерывно (до нескольких десятков тонн в час) под потоком излучения, создаваемого рентгеновской трубкой. РТ возбуждается от источника высокого напряжения, работающего в импульсном режиме. Возникающие сигналы люминесценции фиксируются фотоумножителями (ФЭУ), усиливаются и анализируются на принадлежность к обогащаемому минералу в устройстве регистрации. В случае, когда зарегистрированный сигнал принадлежит алмазу, соответствующая часть руды отделяется («отсекается») от основного потока в концентрат с помощью пневмомеханических устройств с электромагнитным управлением. Остальная руда уходит в «Хвосты», то есть в отвалы, или на дополнительную переработку.

В реальном сепараторе облучение материала осуществляется обычно двумя рентгеновскими трубками, поток может быть разделен на несколько «ручьев», а число фотоприемников и каналов регистрации доходит до 8. Взаимодействие между подсистемами сепаратора, синхронизацию и контроль их функционирования выполняет блок управления. В первых РЛС этот блок был автоматом с жесткой логикой, в современных это программируемый микропроцессорный блок.

Помимо алмазов свойством рентгенолюминесценции обладают и другие сопутствующие минералы. Способность сепаратора выделять сигнал от алмазов на фоне шумов и сигналов от сопутствующих мешающих минералов (селективность) определяется правильной установкой критериев отбора. Реализация процесса отбора осложняется высокой ценностью 


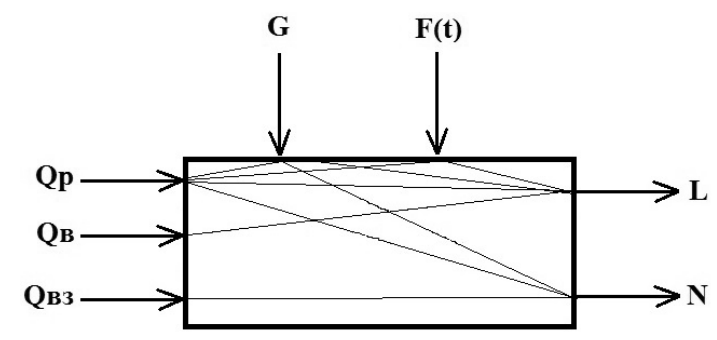

Рис. 3. Технологический процесс рентгенолюминесценции как объект управления

обогащаемого минерала (требуется, как уже отмечалось, извлечь не менее 98-99\% алмазов, имеющихся в исходном материале) и малым временем, отводимым на анализ. Реально это время составляет несколько миллисекунд. По этой причине анализ сигналов люминесценции на соответствие критериям отбора осуществлялся до последнего времени аналоговыми схемами. Недостаток такой реализации - жесткая уставка параметров и фиксированный набор методик разделения алмазов и «пустой» породы.

Проектирование системы автоматического управления. Проектирование комплекса рентгенолюминесцентной сепарации есть выбор переменных параметров оборудования, которые могут изменяться непрерывно (скорость подачи питания, расходы воды в сепаратор, расход воздуха, и др.). Вода в сепаратор подается в зависимости от того, сколько руды поступает в нее. Расход воды - это так называемый ведомый параметр, ведущий - расход руды в сепаратор.

Параметры работы скруббера устанавливаются из соотношения: вода: руда - 0,5 $\div 1: 10$; вода подается в сепаратор в объеме 1,8 м3/ч; производительность сепаратора по руде составляет 45 т/ч; воздух в сепаратор поступает в объеме 1,8 м3/ч.

Технологический процесс рентгенолюминесцентной сепарации, как объект управления характеризуется следующими параметрами (рисунок 3). Входные параметры: подача руды в сепаратор, Qm, т/ч; расход воды в сепаратор, Qw, м3/4; расход воздуха в сепаратор, Qa, м3/ч. Основные возмущающие воздействия: физические свойства руды (прочность, твердость, раскалываемость и т.д.) G,\%; процессы, связанные с износом, заштыбовкой и старением оборудования, $F(t)$,\%. Выходные показатели комплекса: количество отсечек в концентрат, N, шт. (1 отсечка равна примерно 1 кг); уровень заполнения бункера сепаратора, L, М. Управляемые параметры: подача руды в сепаратор, Qm, т/ч. Управляющие параметры: количество отсечек в концентрат, N, шт. Автоматически контролируемые параметры: массовые и объёмные расходы материальных потоков; режимные и диагностические параметры работы сепаратора.

Основные параметры процесса рентгенолюминесцентной сепарации с возможным прямым аппаратно-программным контролем: наличие материала на питателях подачи исходной руды; расход воздуха в сепаратор; массовый или объёмный расход воды в сепаратор; количество отсечек в концентрат. Параметры процесса сепарации с косвенным измерением и контролем: содержание алмазов в концентрате; массовый расход пульпы концентрата сепаратора. Мониторинг оборудования (время работы и простоя основного оборудования) является стандартной расчётно-учётной функцией любой АСУ ТП.

Таким образом, задача управления процессом рентгенолюминесцентной сепарации в общем виде формулируется вектором управляющих воздействий, компенсирующих возмущения на входе агрегата, вектором режимных показателей, получение на выходе агрегата планового (или максимального) количества готового продукта заданного качества (отсечек). Цели управления являются динамическими, основанными на общей экономической стратегии фабрики и работе последующих переделов, а также качестве исходной руды [15, 16]. Они требуют непрерывной коррекции по изменениям показателей.

Модернизация схемы АCУ ТП. Управляющим параметром в данном проекте является расход руды и воды в сепараторе. В качестве вторичных приборов будут использованы 8-канальные измерители-регуляторы и аналоговые модули ввода. Токовые сигналы будут подаваться на аналоговые модули ввода. Далее приборы объединяются сетью на базе интерфейса и через преобразователи, данные о работе сепаратора передаются на автоматизированное рабочее место оператора.

Нижний (полевой) уровень АСУ ТП обеспечивает сбор данных о параметрах технологического процесса и состояния оборудования, реализует управляющие 
Помещение Рщ10 СЦКРЛС отм.+21.500

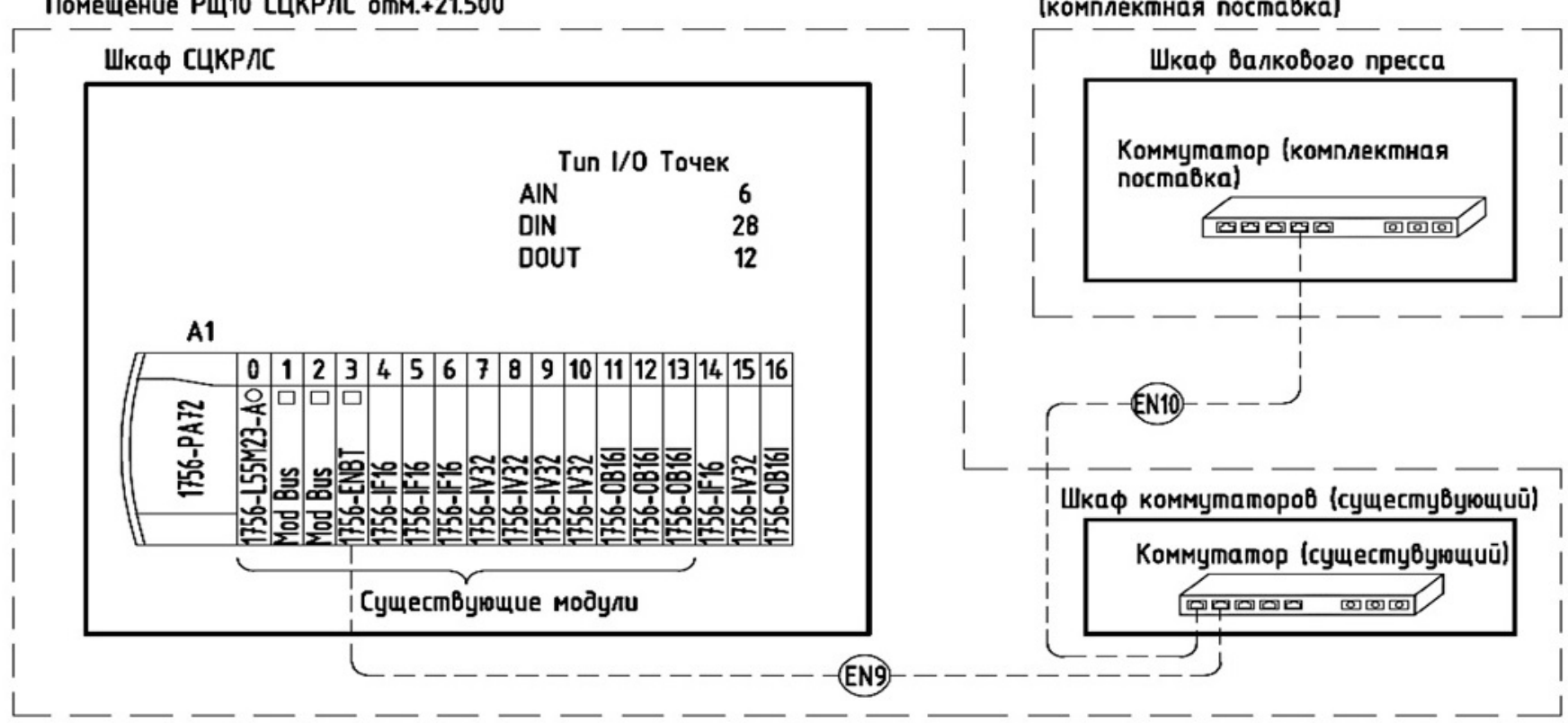
(комппектная nоставка)
Помещение серверной отм.+11.000

Шкаф IT 19"

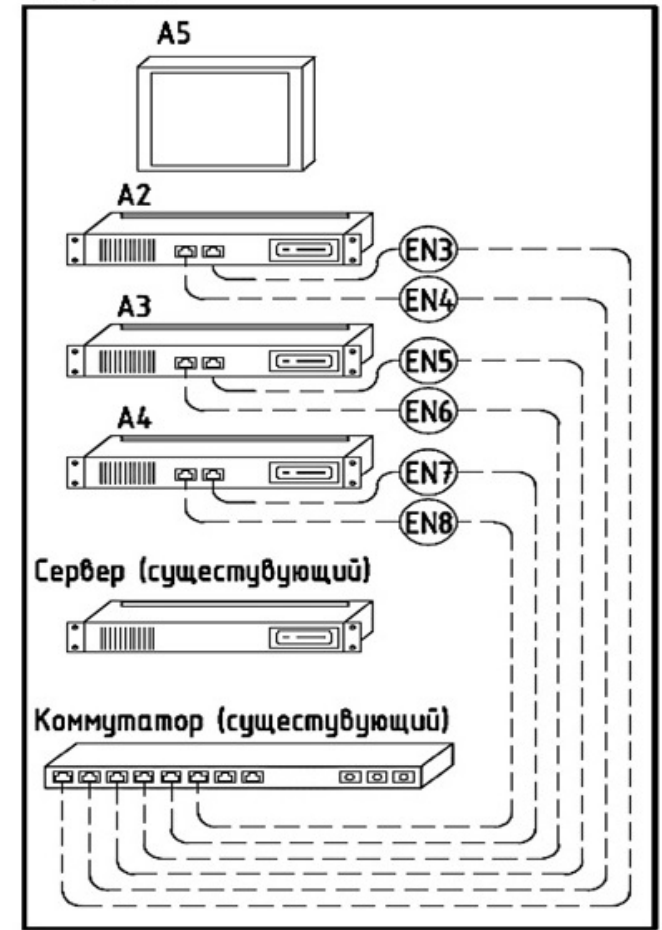

Площадка Өалковых прессов отм.+4.700

Помещение цДП отм.+5.000

Шкаф коммутаторов (сущестувиющич̄)

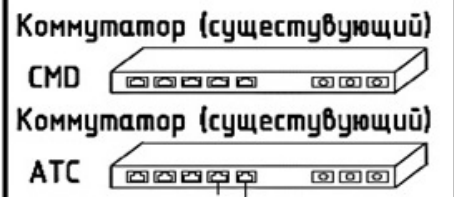

ATC

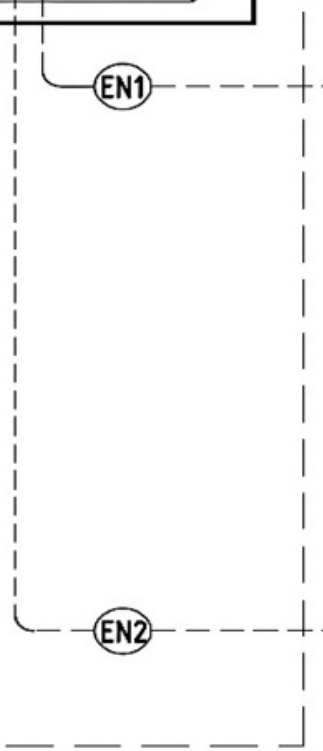

APM onepamopa цдп

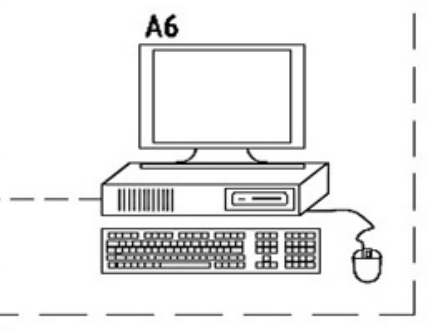

Помещение начальника КИПчА отм. +24.000

АРМ начальника КИПчА

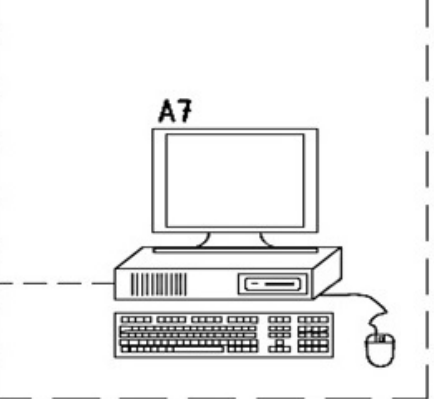

Рис. 4. Структурная схема АСУ ТП

воздействия. Основными техническими средствами нижнего уровня являются датчики и исполнительные устройства, станции распределенного ввода/вывода, пускатели, концевые выключатели, преобразователи частоты $[17,18]$.
Средний уровень обеспечивает управление агрегатами системы в различных режимах, контролирует параметры и производит обработку аварийных ситуаций. Средний уровень состоит из шкафа управления (ШУ) и силового шкафа (ШС). ШУ обеспечивает ввод 
и измерение температурных и токовых сигналов, формирует команды на включение и отключение технологических узлов. ШС по командам, поступающим от ШУ, включает и отключает технологические узлы. Средний уровень построен на базе Logix. На среднем уровне реализуются задачи автоматического управления и регулирования, пуска и останова оборудования, логико-командного управления, аварийных отключений и защит. Средний уровень реализуется на основе ПлК.

Верхний уровень АСУ ТП реализуется на базе серверов, операторских (рабочих) и инженерных станций. Компьютеры верхнего уровня и контроллеры объединены дублированной сетью Ethernet. На рисунке 4 представлена структурная схема АСУ ТП.

Цель разработки АСУ ТП - замена существующих, морально устаревших средств управления технологическим процессом и повышение надежности функционирования системы; расширение функций автоматического и автоматизированного контроля и управления; повышение качества управления технологическим процессом, а также повышение надежности АСУ ТП. Система автоматического контроля позволяет стабилизировать основные параметры процесса, своевременно и достоверно обеспечить информацией обслуживающий персонал, защитить оборудование при возникновении предаварийных ситуаций [19].

Блок человеко-машинного интерфейса совмещает в себе функции управления и мониторинга сепаратора, а также обработку сигналов люминесценции, поступающих от ФПУ. Блок представляет собой промышленный корпус RACK-305GW, в который установлены четыре модуля: процессорный модуль с интерфейсом PICMG 1.3, два функциональных модуля с интерфейсом PCI (быстрый АЦП и ЦАП для обработки сигналов люминесценции) и модуль расширитель коммуникационных портов с интерфейсом PCІ. Связь между модулями осуществляется через пассивную объединительную плату. Посадочные места (слоты модулей) индивидуальны модули должны устанавливаться на определенные позиции. Питание блока осуществляется от встроенного источника питания АCE-A130B (АТХ). Блок человеко-машинного интерфейса функционирует в соответствии с программой, записанной на твердотельном накопителе, который устанавливается в специальный разъем mSATA на плате процессорного модуля. Программное обеспечение блока человеко-машинного интерфейса - это основа программное обеспечение сепаратора. ПО работает в программной среде реального времени QNX. Такая организация позволяет «одновременно» вести два процесса: с одной стороны, это представление на экране монитора символов многофункциональной панели мониторинга и управления, работа с вирту- альными кнопками управления, а с другой стороны непрерывная (фоновая) обработка входных сигналов на предмет обнаружения сигнала полезного минерала - алмаза [20].

На двери CAУ закреплен монитор FPM-7151Т с сенсорным экраном, который подключен к блоку человеко-машинного интерфейса. Вся информация с блока человеко-машинного интерфейса передается на экран монитора. Органы управления и индикации появляются на экране монитора после загрузки программы (процесс загрузки программы начинается автоматически после включения питания сепаратора и завершается примерно за 1,5 минуты).

При постановке задач оптимизации наряду с критериями должны быть заданы ограничения на все параметры и переменные технологического процесса, допустимые изменения, которые определяют функционирование технологического процесса. Достижение поставленных задач осуществляется реализацией функций. На вычислительную технику возложены задачи управления пуском и остановом технологического оборудования, контроля его состояния и защиты от перегрузок, поддержания заданного режима работы оборудования и стабилизации отдельных технологических параметров, оптимизации качественных и количественных показателей работы отдельных агрегатов.

Выбор конкретных типов автоматических устройств рекомендуется проводить, исходя из следующих соображений:

- для контроля и регулирования одинаковых параметров технологического процесса следует применять одинаковые автоматические устройства, что облегчает их приобретение, настройку, ремонт и эксплуатацию;

- следует отдавать предпочтение автоматическим устройствам серийного производства;

- при большом числе одинаковых параметров контроля следует применять многоточечные приборы и машины централизованного контроля;

- при автоматизации сложных технологических процессов следует использовать вычислительные и управляющие машины;

- класс точности приборов должен соответствовать технологическим требованиям;

- для местного контроля рекомендуется применять простые и надежные приборы, так как они часто функционируют в неблагоприятных условиях;

- для автоматизации технологических аппаратов с агрессивными средами следует предусматривать установку специальных приборов, а в слу- 


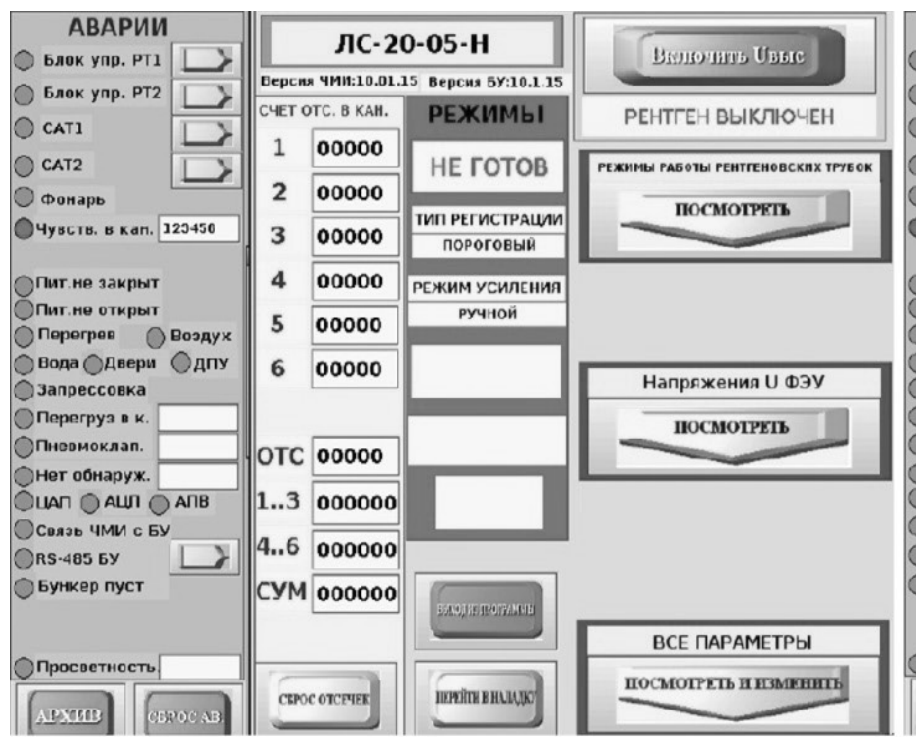

a)

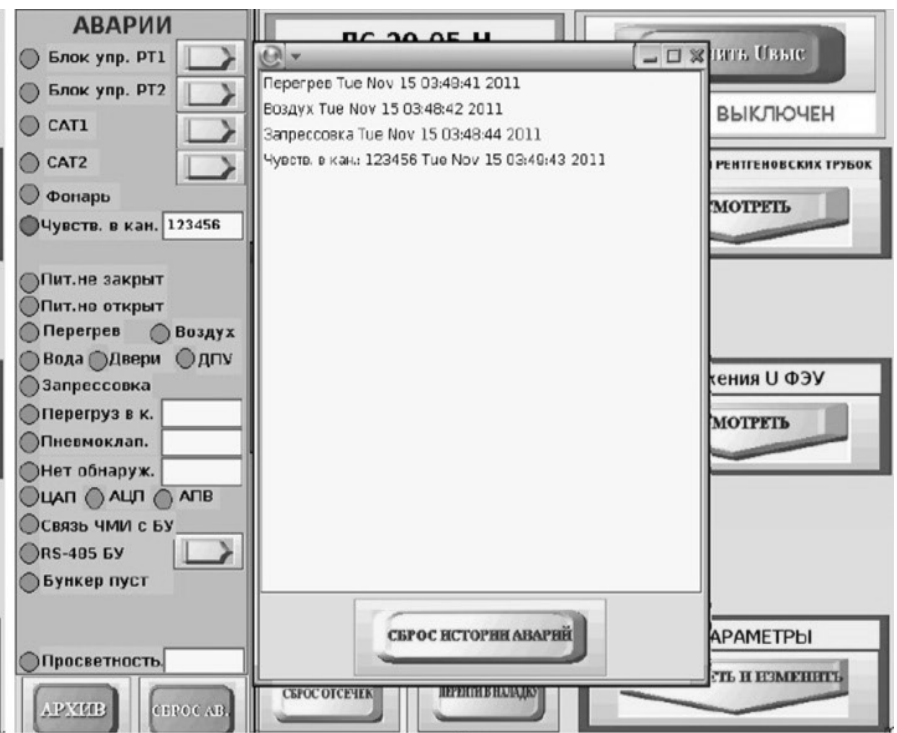

б)

Рис. 5. Меню сепаратора с режимом «НЕ ГОТОВ» (а) и историей аварий (б)

чае применения приборов в нормальном исполнении необходимо защитить их.

Модернизация интерфейса оператора. Программирование ПЛК осуществляем в интегрированной информационной системе для управления промышленным производством с помощью программного обеспечение RSLogix 5000. Разработку автоматизированного рабочего места (АРМ) оператора-технолога осуществляем в интегрированной информационной системе для управления промышленным производством FactoryTalk View. Особенностью FactoryTalk View является «технология единой линии программирования», то есть возможность разработки всех модулей АСУ при помощи одного инструмента. Технология единой линии программирования позволяет в рамках одного проекта создавать средства человеко-машинного интерфейса, системы учёта ресурсов, программировать промышленные контроллеры и разрабатывать web-интерфейс. Для этого в инструментальную систему FactoryTalk View встроены специализированные редакторы.

Далее представлены видеокадры АРМ оператора-технолога, на которых отображены параметры процесса управления рентгенолюминесцентного сепаратора и параметры диагностики. При включении сепаратора открывается исходная страница - НЕ ГОТОВ, рисунок 5 (а).

Изображение на экране монитора разделено на три зоны: центральную, где обозначены тип сепаратора, режимы функционирования, показатели работы; правую, где имеется доступ к параметрам (в этой зоне вверху отдельно выделена зона управления высоким напряжением на РТ) и левую - зону сообщений об аварийных ситуациях. В каждой зоне выделены окна сообщений и «объемные» кнопки управления. Легкое нажатие пальцем на экран в месте расположения кнопки (на экране при этом визуально изображается ее «утапливание») без усилий в течение 0,5-1 секунд до возникновения реакции на прикосновение приводит к соответствующему действию. В процессе управления и мониторинга сепаратора вид панели (экранная форма) меняется.

Режимы работы сепаратора: НЕ ГОТОВ - режим сепаратора, при котором присутствует хотя бы один из признаков аварии; при снятии признака аварии сепаратор переходит в режим РАБОТА; РАБОТА - основной режим работы сепаратора, использование сепаратора по назначению; НАЛАДКА - режим работы сепаратора, при котором осуществляется проверка и настройка узлов и систем сепаратора; ГОТОВ - режим работы сепаратора, при котором выключается подача материала в сепаратор по команде с диспетчерского пульта фабрики; при этом все системы сепаратора готовы к работе; при разрешении подачи материала сепаратор переходит в режим РАБОТА; НАЛ. ПУЛЬТ - режим работы от выносного ПУ; активируются кнопки пультовые кнопки управления, запрещается подача высокого напряжения на РТ. Этот режим применяется для проверки систем сепаратора непосредственно около МС. 
При открывании любой двери САУ появляется уведомление. При прикосновении к нему, он исчезает, но через 5 мин, если двери остаются открытыми он появляется снова. В архив записываются: наименование аварии, день, месяц, дата и время каждой аварии, рисунок 5 (б).

За счет разработки SCADA-системы управления работой рентгенолюминесцентного сепаратора в пакете FactoryTalk View, были решены задачи по повышению надежности функционирования системы противоаварийной защиты, расширение функций автоматического и автоматизированного контроля и управления, а также повышения качества анализа функционирования объекта (накопление информации, расчет экономических показателей; анализ работы оперативного персонала в статистическом, переходном и аварийном режимах процесса).

\section{Зак^ючение}

Таким образом, проектирование и внедрением АСУ ТП процесса рентгенолюминесцентной сепарации алмазосодержащих руд повысило условия безопасного ведения процесса. В первую очередь это связано с введение автоматизированного способа управления, что сводит к минимуму вероятности возникновений внештатной ситуации. Время нахождения персонала в опасных зонах технологической линии заметно снижается, а, следовательно, снижается вероятность получения травм и хронических заболеваний персоналом. Путем внедрения АСУ ТП рентгенолюминесцентной сепарации алмазосодержащих руд, мы добились снижения затрат на переработку 1 т сырья. Использование режимов и настроек сепараторов позволило сократить расходы на переработку сырья и достичь общего роста производительности труда.

\section{ЛИТЕРАТУРА}

1. Акишев А.Н., Колганов В.Ф., Зырянов И.В. Классификация кимберлитовых месторождений на основе новых аналитических критериев // Горный журнал. - 2014. — № 9.- С. 78-81.

2. Чаадаев А.С., Черепнов А.Н., Зырянов И.В., Бондаренко И.Ф. Перспективные направления развития технологий добычи и переработки алмазосодержащих руд в АК «АЛРОСА» (ПАО) // Горный журнал.— 2016.— № 2.— C. 56-61. D0l: 10.17580/gzh.2016.02.11

3. Bebikhov Y.V., Podkamenniy Y.A., Golikov V.V., Spiridonov V.M. On the Issue of Complex Automation of Mining Operations in the Diamond Mining Industry // 2020 International Multi-Conference on Industrial Engineering and Modern Technologies (FarEastCon 2020). 2020. No. 9271623. D0I: 10.1109/ FarEastCon50210.2020.9271623

4. Chanturia V.A., Kovalchuk O.E., Morozov V.V., Dvoichenkova G.P. Modification of Diamond Crystal Luminescence Parameters Using Luminophore-Containing Emulsions // IOP Conference Series: Earth and Environmental Science. 2020. V. 459. Is. 5. No. 052097. DOI: 10.1088/1755-1315/459/5/052097

5. Imangulov S.V., Yakovlev V.N., Zyryanov I.V., Makalin I.A., Ivanov A.V. Low-luminescent diamonds recovery using X-ray transmission separation technology // IMPC2018-29th International Mineral Processing Congress. 2019. P. 909-914.

6. Миронов В.П. Повышение эффективности рентгенолюминесцентной сепарации алмазов путем фильтрации спектра // 0богащение руд.- - 2017.№ 2 (368). - C. 32-37. DOI: 10.17580/or.2017.02.06

7. Chen C., Xie Y., Yan X., Ahmed M., Lupoi R., Wang J., Ren Z., Liao H., Yin S. Tribological properties of Al/diamond composites produced by cold spray additive manufacturing // Additive Manufacturing. 2020. V. 36. No. 101434. D0I: 10.1016/j.addma.2020.101434

8. Tolmachev 0., Urunov A., Muminova S., Dvoichenkova G., Davydov I. Review of unconventional hydrocarbon resources: Production technologies and opportunities for development // Mining of Mineral Deposits. 2020. V. 14. Is. 4. P. 113-121. D0I: 10.33271/mining14.04.113

9. Makvandi S., Pagé P., Tremblay J., Girard R. Exploration for platinum-group minerals in till: A new approach to the recovery, counting, mineral identification and chemical characterization // Minerals. 2021. V. 11. Is. 3. No. 264. D0I: $10.3390 / \mathrm{min} 11030264$

10. Podkamenniy Y.A., Donskoy A.A. Analysis of the Process of Washing Diamond-Bearing Ore after Crushing as an Object of Automation // 2020 International Multi-Conference on Industrial Engineering and Modern Technologies (FarEastCon 2020). 2020. No. 9271086. D0I: 10.1109/FarEastCon50210.2020.9271086

11. Podkamenniy Y.A., Karatova P.P., Kadyrbekova E.A. Analysis of the Preparation Process of Ointment for Sticky Separation of the Concentrating Plant as an Object of Automation // 2020 International Multi-Conference on Industrial Engineering and Modern Technologies (FarEastCon 2020). 2020. N0. 9271211. D0I: 10.1109/ FarEastCon50210.2020.9271211

12. Srinivas J., Das A.K., Wazid M., Vasilakos A.V. Designing Secure User Authentication Protocol for Big Data Collection in IoT-Based Intelligent Transportation System // IEEE Internet of Things Journal. 2021. V. 8. Is. 9. P. 7727-7744. D0I: 10.1109/JI0T.2020.3040938

13. Mahmoodi-k M., Montazeri M., Madanipour V. Simultaneous multi-objective optimization of a PHEV power management system and component sizing in real world traffic condition // Energy. 2021. V. 233. No. 121111. D0I: 10.1016/j.energy.2021.121111

14. Srinivas J., Das A.K., Li X., Khan M.K., Jo M. Designing Anonymous Signature-Based Authenticated Key Exchange Scheme for Internet of Things-Enabled Smart Grid Systems // IEEE Transactions on Industrial Informatics. 2021. V. 17. Is. 7. P. 4425-4436. D0I: 10.1109/TII.2020.3011849

15. Хурэлчулуун И., Морозов В.В., Николаева Т.С., Круглов В.Н. Применение визиометрического анализа гранулометрического состава руды для автоматизированного управления процессом дробления // Руды и металлы.— 2019. - № 1._ C. 67-73. D01: 10.24411/0869-5997-2019- 
16. Августинович В.Г., Кузнецова Т.А., Нугуманов А.Д. Разработка нейронных систем мониторинга и управления эмиссией вредных веществ для газотурбинных газоперекачивающих агрегатов и электростанций // Известия Томского политехнического университета. Инжиниринг георесурсов.2019. — Т. 330.— № 8.—C. 7-17. D0I: 10.18799/24131830/2019/8/2207

17. Егоров А.Н., Семёнов А.С., Федоров 0.В. Практический опыт применения преобразователей частоты Power Flex 7000 в горнодобывающей промышленности // Труды НГТУ им. Р.Е. Алексеева.— 2017.— № 4 (119). — С. 86-93.

18. Семёнов А.С., Егоров А.Н., Харитонов Я.С., Федоров О.В. Оценка электромагнитной совместимости высоковольтных преобразователей частоты в электротехнических комплексах // Вестник Казанского государственного энергетического университета.— 2019. — Т. 11. — № 4 (44). — С. 64-75.

19. Программа инновационного развития и технологической модернизации АK «АЛPOCА» (ПАО) (редакция 2020 г.). [Электронный ресурс]. URL: http:// www.alrosa.ru/wp-content/uploads/2014/06/паспорт-ПИРитМ-2020-1.pdf (дата обращения: 05.07.2021).

20. Бармин И.С., Морозов В.В., Поливанская В.В. Совершенствование реагентных режимов для извлечения фосфатных минералов из тонких классов руд и техногенных продуктов // Горный информационно-аналитический бюллетень (научно-технический журнал). - 2020.— № 1. - C. 149-159. D0l: 10.25018/0236-1493-2020-1-0-149-159

( ) Подкаменный Юрий Александрович ( mirniy.yuriy@mail.ru ), Бебихов Юрий Владимирович ( bebikhov.yura@mail.ru ), Семёнов Александр Сергеевич ( sash-alex@yandex.ru ), Спиридонов Валентин Михайлович ( kafeiagp@rambler.ru ).

Журнал «Современная наука: актуальные проблемы теории и практики»

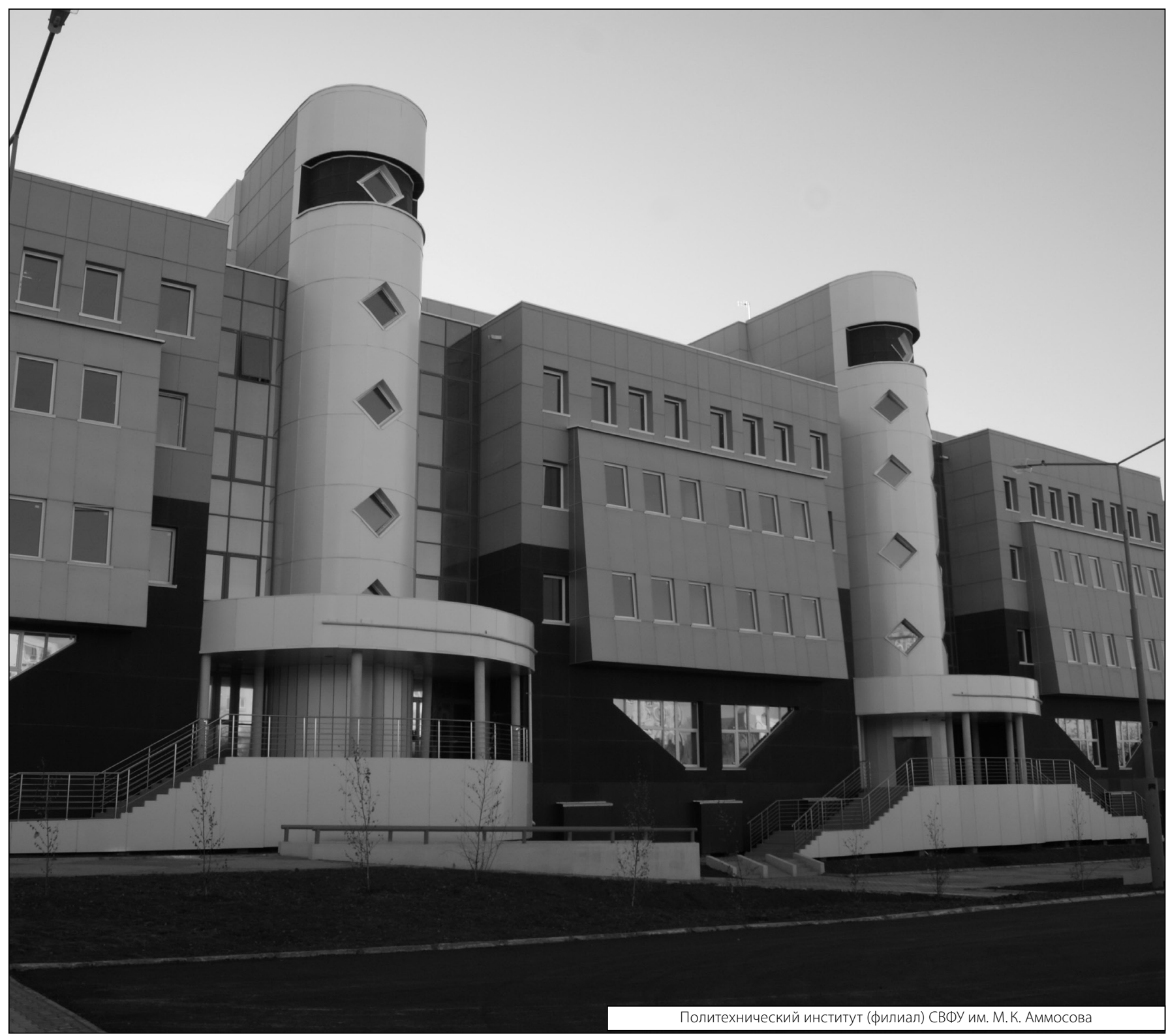

